LATOUR, Bruno. (2005), Reassembling the social: an introduction to actor-network theory. Oxford, Oxford University Press.

POCHMANN, Márcio et al. (2005), Atlas da exclusão social. Vol. 3: Os ricos no Brasil. São Paulo, Cortez.

STRATHERN, Marilyn. (1988), The gender of the gift: problems with women and problems with society in Melanesia. Berkeley, University of California Press.

TELLES, Vera da Silva. (2006), "Debates: a cidade como questão", in V. S. Telles e R. Cabanes (orgs.), Nas tramas da cidade: trajetórias urbanas e seus territórios, São Paulo, Humanitas.

CATARINA MORAWSKA VIANNA

é professora do Programa de Pós-graduação em antropologia social da

Universidade Federal de São Carlos. E-mail: <morawskavianna@yahoo.com>.

\section{Rediscutindo os limites do crescimento econômico}

Philippe LÉNA \& Elimar PINHEIRO DO NASCIMENTO (orgs.). Enfrentando os limites do crescimento: sustentabilidade, decrescimento e prosperidade. Rio de Janeiro, Garamond, 2012. 444 páginas.

\section{Paulo Renan Rodrigues de França}

A questão ambiental é hoje uma das principais problemáticas nos debates sobre o futuro da humanidade. As discussões em torno dos limites físicos do planeta não se restringem a um pequeno número de países e de profissionais, sendo um campo vasto para análises, propostas de ação e produção acadêmica.

A coletânea Enfrentando os limites do crescimento, organizada pelo geógrafo e sociólogo francês, Philippe Léna em parceria com o também sociólogo brasileiro Elimar Pinheiro do Nascimento, é uma importante contribuição para o debate acadêmico sobre sustentabilidade no Brasil; o livro conta com a participação de 22 autores, além dos dois organizadores, que em seus referentes países, contribuem ativamente para o avanço das discussões em torno dos limites do crescimento.

Desde o artigo inicial de Philippe Léna, podemos ver a posição que vai demarcar grande parte do livro: a crítica ao crescimento econômico, e também ao desenvolvimento sustentável. Este termo, que para muitos é apenas um oximoro, tornou-se hegemônico quando, em 1987, foi elaborado o documento "Nosso futuro comum" (mais conhecido como Relatório Brundtland), pela Comissão Mundial sobre Meio Ambiente e Desenvolvimento. Phillipe Léna argumenta que "o pensamento social-ecológico alcançou, ao mesmo tempo, o reconhecimento internacional e um grau mais elevado ainda de banalização" (p. 27), através do conceito de desenvolvimento sustentável (DS).

Tal conceito passou a ser a nova moeda de tro$\mathrm{ca}$, a meta a ser alcançada, o discurso feito "por todas as agências internacionais, os governos e até as empresas (inclusive as mais predatórias)" (p. 27). Entretanto, também serviu para por em pauta os problemas dos limites do crescimento e é defendido por muitos atores sociais, por ser "a única forma 
de ganhar visibilidade, participar de negociaçóes nacionais e internacionais e conseguir financiar projetos" (p. 33).

Por não fugir à lógica do crescimento e das políticas voltadas a este paradigma, o desenvolvimento sustentável é bastante criticado por ambientalistas, que além de sugerirem uma mudança radical no âmbito da sustentabilidade, propóem uma mudança social profunda. Uma das críticas ao DS, que vem ganhando relevância é o slogan político do decrescimento. Serge Latouche, em seu ensaio, deixa bem claro que o decrescimento (decroissance, em francês) não é um conceito e também não significa o "oposto simétrico do crescimento" (p. 48) Pode-se dizer que o decrescimento é uma crítica à estrutura da sociedade ocidental, alimentada pelo consumismo desenfreado, pelo gasto energético desmedido. Essa noção de crescimento, segundo Latouche, causa pelo menos três efeitos negativos: "ela produz um aumento das desigualdades e injustiças; ela cria um bem-estar amplamente ilusório; ela não suscita, mesmo para os que mais se beneficiam, uma sociedade amigável e sim uma antissociedade que padece de sua riqueza” (p. 47).

Nicolas Georgescu-Rogen é um dos precursores da ideia de decrescimento. Em seus estudos, o "pai fundador da economia ecológica" (p. 65) criticou o modelo de economia convencional, que excluía completamente a variável ambiental das análises econômicas. No texto de André Cechin (pp. 349-367), ele mostra que Georgescu apontava para o erro de tratar os fatores de produção como semelhantes, o que levaria a outro erro, o da substituição infinita por supor que "o fluxo de recursos naturais pode ser facilmente e indefinidamente substituído por capital" (p. 354).

Por ser uma ideia em construção, o decrescimento ainda é visto com desconfiança por alguns; para outros é visto como um ponto de partida para sairmos de uma sociedade apoiada na acumulação de bens materiais em detrimento dos bens naturais, da justiça social, dos laços sociais etc. Para Mauro Bonaiuti (pp. 79-105), estamos a caminho da grande transição, uma mudança profunda nas relações do ser humano com seu próximo e do ser humano com o meio ambiente. Contudo, para tal é preciso que se reconheça que o modo de vida ca- pitalista não é compatível com os limites de físicos do planeta e é nocivo para as relações sociais. Não são poucas as pessoas que têm esta tese bem fixada em suas mentes; em contrapartida, como o autor reconhece, a classe dominante não pretende mudar tão facilmente de ideia, e tenta a todo custo nos vender uma sociedade alienada. $E$, com ela, a ideia de que as constantes crises do sistema são apenas normais e passageiras.

O livro também enfatiza as questôes relativas ao PIB (Produto Interno Bruto), principal indicador de prosperidade e desenvolvimento das nações. José Eli da Veiga e Liz-Rejane Issberner demonstram que este indicador é incompatível para analisar o desenvolvimento de um país. Para ilustrar esta ideia, usam o exemplo da economia brasileira, que de 1980 até o presente não teve um crescimento econômico tão grande como o seu desenvolvimento em outras áreas, particularmente a social.

Os autores reforçam a ideia de que crescimento econômico é diferente de desenvolvimento. É necessário encontrar outros indicadores de prosperidade, que ultrapassem o PIB. Indicadores que não levem somente em consideração o aumento da renda per capita, mas que busquem compreender os reais ganhos de qualidade de vida, bem-estar e a preservação dos ecossistemas, garantindo a existência dos recursos não renováveis que, na maioria das vezes, são a matéria-prima mais utilizada na produção.

$\mathrm{O}$ artigo de Gilbert Rist demonstra que de tempos em tempos as teorias do desenvolvimento são sobrepostas por outras. Antes, a preocupação das sociedades capitalistas ocidentais era que seu padrão de desenvolvimento deveria ser levado para outros países, , mas esta ideia já não é consensual:

Novas teorias mostravam que nos tornáramos "ricos" por termos explorado os "pobres", dependentes de um sistema injusto, que era preciso modificar para restaurar um equilíbrio pervertido: ao nos desenvolver, não teríamos contribuído a criar o subdesenvolvimento e enfraquecer as chances desses países seguirem o caminho que tínhamos traçado? Falava-se, então, em quebrar as correntes da dependência, recuperar a autonomia nacional e reapropriar-se do seu destino (p. 135). 
Assim, como o desenvolvimento não foi a solução para os diversos problemas do mundo, será possível que o decrescimento virá a ser uma nova panaceia ou apenas mais um paliativo? $\mathrm{O}$ autor responde: "convém decrescer, limitar nossos apetites, parar de achar que 'mais = melhor'. É preciso incentivar tudo aquilo que contribui para limitar a obsessão pelo crescimento”. Entretanto, segundo Rist, é preciso que os objecteurs de croissance critiquem não somente o modo como consumimos, mas também a própria teoria econômica dominante. E prossegue afirmando que o decrescimento é uma necessidade nos países tanto do Norte como do Sul, porém para que os reais efeitos deste movimento sejam sentidos, ele não pode "se contentar em trapacear o 'sistema'. Pelo contrário, ele deve contestar seu fundamento" (p. 146), para que não seja mais um paliativo no meio de outros tantos.

$\mathrm{O}$ artigo de Rist ecoa páginas depois no texto de Miguel Benasayag e Angélique del Rey, que aborda a questão de como conciliar nos países do Sul justiça social e decrescimento. Sugere-se que os países mais pobres devam seguir o exemplo dos mais ricos, mas como desacelerar a economia em países que precisam do desenvolvimento para garantir uma economia mais estável e, portanto, assegurar a justiça social? "Daí advém a contradição entre as duas justiças, social e ecológica, e a consequente dificuldade de se chegar a um acordo entre pessoas envolvidas com ecologia, no Norte e no Sul” (p. 290).

Com efeito, o livro traz diversos pontos de vista sobre a questão ecológica, endossa as críticas ao modelo capitalista (em especial Michel Lowy, que, como alternativa, aponta o ecossocialismo), levanta questões importantes sobre a justiça social e ambiental, faz críticas contundentes ao desenvolvimento sustentável e promove a teoria do decrescimento. Isso não significa que não haja indagação sobre a viabilidade de tal teoria na sociedade contemporânea, como discutido no artigo de Onofrio Romano e Vincenzo Lauriola (pp. 391-413).

Já Elimar Nascimento, em ensaio que encerra a coletânea, afirma que as questôes em torno da sustentabilidade deixaram de ser meros conceitos, uma noção ou valor, para se tornar "uma arena de disputa com objetos, agentes e regras próprias” (p. 416). Tendo isso em mente, o autor aplica o conceito de campo - um dos pilares da obra de Pierre Bourdieu - à sustentabilidade, estabelecendo os critérios que este novo campo possui e quais as exigências para nele ingressar. Trata-se, em primeiro lugar, de um campo interdisciplinar e multidimensional, envolvendo questões não só ambientais, mas também sociais, políticas e econômicas. Em contrapartida, diante da ameaça que espreita a humanidade, as diferentes vozes deste debate convergem no sentido de propor e analisar possibilidades de superação. É isso que caracterizaria a porta de entrada para o campo da sustentabilidade.

Os autores desta coletânea, não obstante ideias e perspectivas diversas, compartilham, pois, da preocupação com os limites do crescimento e da certeza de que algo precisa ser feito para a preservação da espécie humana; o planeta, ao contrário do que acreditamos, pode permanecer muito bem sem nós.

PAULO RENAN RODRIGUES DE FRANÇA é mestrando em desenvolvimento sustentável na Universidade de Brasília e bacharel em turismo pela Universidade do Estado do Amazonas.

E-mail: <p_renan10@hotmail.com>. 